\title{
Exploitation of the serpentine leafminer Liriomyza trifolii and tomato leafminer L. bryoniae (Diptera: Agromyzidae) by the parasitoid Gronotoma micromorpha (Hymenoptera: Eucoilidae)
}

\author{
Yoshinisa ABE \\ Laboratory of Applied Entomology, Graduate School of Agriculture, Kyoto Prefectural University, Shimogamo, Kyoto 606-8522, \\ Japan; e-mail: y_abe@kpu.ac.jp
}

\begin{abstract}
Key words. Biological control, Liriomyza, Agromyzidae, Gronotoma, Eucoilidae, host acceptance, host suitability, survival, development
\end{abstract}

\begin{abstract}
The developmental time and size of a solitary koinobiont parasitoid, Gronotoma micromorpha (Perkins) (Hymenoptera: Eucoilidae), were measured in two host species: the serpentine leafminer, Liriomyza trifolii (Burgess) (Diptera: Agromyzidae) and tomato leafminer, L. bryoniae (Kaltenbach). There was no significant difference in the developmental time of G. micromorpha in these two hosts. However, significantly larger G. micromorpha adults emerged from L. bryoniae than from L. trifolii puparia. Dissection of larvae revealed that when offered a choice G. micromorpha accepted larvae of $L$. bryoniae more often than those of $L$. trifolii. The number of wasps emerging from parasitized hosts did not differ significantly between host species. These results indicate that L. trifolii and L. bryoniae are both acceptable and suitable hosts for G. micromorpha. Gronotoma micromorpha may be a useful biological control agent of both L. trifolii and L. bryoniae.
\end{abstract}

\section{INTRODUCTION}

The serpentine leafminer, Liriomyza trifolii (Burgess) and tomato leafminer, L. bryoniae (Kaltenbach) often coexist in greenhouses and are serious pests of tomatoes in Europe (Spencer, 1973; Minkenberg \& van Lenteren, 1986) and Japan (Abe \& Kawahara, 2001). Leaf mining by Liriomyza larvae reduces photosynthesis and, as a result, crop yield (Malais \& Ravensberg, 1991). The relationship between injury by L. bryoniae and yield loss in tomatoes is known (Ledieu \& Helyer, 1985).

Liriomyza trifolii is indigenous to the New World (Spencer, 1973), but has extended its geographical range to Asia, Africa and Europe (Saito, 1997). In contrast, L. bryoniae is of Palaearctic origin (Sasakawa, 1961; Spencer, 1973). Liriomyza trifolii and L. bryoniae are similar in morphology, so it is not easy for growers to distinguish between them. Both leafminers are polyphagous attacking vegetables and ornamentals (Minkenberg \& van Lenteren, 1986). The total developmental times (oviposition to adult emergence) of L. trifolii and L. bryoniae on kidney bean, Phaseolus vulgaris L., are 16.5 and 19.3 days, respectively, at $25^{\circ} \mathrm{C}$ (Tokumaru \& Abe, 2003).

The braconid Dacnusa sibirica Telenga and the eulophid Diglyphus isaea (Walker), originally used for the biological control of L. trifolii and L. bryoniae in Europe, have been imported and released in Japanese greenhouses to control Liriomyza leafminers (Ozawa et al., 2001). Japanese greenhouses are usually small and kept at high temperatures and humidities (Yano, 1993). The effectiveness of D. sibirica may be restricted in Japan, because this wasp is less effective at controlling leafminers on tomato at high temperatures (Minkenberg, 1990).

In contrast to $D$. sibirica, $D$. isaea is a more effective parasitoid at high temperatures (Minkenberg, 1989).
Diglyphus isaea occurs in Japan, where it is the dominant parasitoid attacking the garden pea leafminer, Chromatomyia horticola (Gourea) (Takada \& Kamijo, 1979). The potential risks of introducing exotic natural enemies has recently received attention and the potential of hybridization needs to be included in risk analysis (van Lenteren et al., 2003). Many naturalists believe strongly that native genotypes should be preserved and that introduction of foreign genes constitutes genetic pollution (Williamson, 1996). Greenhouses in Japan are not completely insect proof (Yano, 1993) so hybridization between European and Japanese populations of D. isaea may have occurred.

Male-biased sex ratios may be common in Diglyphus (Heinz \& Parrella, 1990). Such male-biased sex ratios need to be carefully monitored and manipulated in the mass production of these parasitoids (Rathman et al., 1991). Moreover, in mass rearing thelytokous wasps do not use expensive hosts for the production of males (Stouthamer, 1993). Thus, thelytokous parasitoids are more suited to mass production than arrhenotokous ones (Abe \& Tahara, 2003).

The solitary koinobiont parasitoid, Gronotoma micromorpha (Perkins), occurs in subtropical regions, i.e., Okinawa, Florida, Hawaii, Guam and Tahiti (Yoshimoto, 1963; Beardsley, 1988; Abe \& Konishi, 2004), and appears to be the dominant parasitoid of L. trifolii on Okinawa, Japan (Konishi, 1998), and Guam, USA (Johnson, 1993). Under laboratory conditions, this parasitoid has a high net reproductive rate when it parasitizes the host $L$. trifolii (Abe \& Tahara, 2003). Wolbachia infection induces thelytoky in this wasp (Arakaki et al., 2001). This thelytokous wasp is an egg-pupal and larval-pupal parasitoid (Abe, 2001). Gronotoma micromorpha can develop at most of the temperatures at which L. trifolii damages 
crops, and the combination of high temperature and short photoperiod found in Japanese greenhouses in winter does not adversely affect its development (Abe \& Tahara, 2003). The developmental rate of $G$. micromorpha increases linearly with increasing temperature between 18 and $30^{\circ} \mathrm{C}$. The lower thermal thresholds for complete development and oviposition are $11.7^{\circ} \mathrm{C}$ and approximately $18^{\circ} \mathrm{C}$, respectively (Abe \& Tahara, 2003). These results indicate that should G. micromorpha escape from greenhouses, where they were released for controlling leafminers, they cannot overwinter in Japan, except in the subtropical regions. To clarify the potential of G. micromorpha as a biological control agent of $L$. trifolii and $L$. bryoniae, the acceptability and suitability of these two Liriomyza species for this parasitoid were determined.

\section{MATERIAL AND METHODS}

\section{Insects and plants}

Laboratory cultures of G. micromorpha and L. trifolii were established from parasitized and non-parasitized L. trifolii larvae collected in Itoman City, Okinawa Prefecture, Japan, in April 1998 (Abe, 2001). The maintenance of stock colonies, and preparation of hosts and parasitoids for experiments are described in more detail in a previous paper (Abe, 2001). A laboratory culture of $L$. bryoniae was established from individuals collected from leaves of tomato plants in Kamigamo, Kyoto City, Japan, in June 1998. Phaseolus vulgaris was used as a host plant for colony maintenance and in all the experiments. Colony maintenance and all experiments were conducted at $25^{\circ} \mathrm{C}$ under a $15 \mathrm{~L}: 9 \mathrm{D}$ photoperiod.

The effects of host (L. trifolii) age at oviposition ( 0 to 4 days $=$ egg to mature larva) on percentage emergence and developmental time of G. micromorpha were previously determined in the laboratory (Abe, 2001). There was no significant difference in percentage emergence among host ages. However, the developmental time was significantly shorter in 3- or 4-day-old larvae, suggesting that mature larvae are a more suitable host stage for G. micromorpha. The mature larvae of $L$. bryoniae are similarly more suitable than earlier stages as a host for $G$. micromorpha (Abe, Y., unpubl.). Larvae of L. trifolii developing on $P$. vulgaris leaves pupate after 5-6 days at $25^{\circ} \mathrm{C}$ (Abe, 2001), and those of L. bryoniae after 6-7 days (Abe, Y., unpubl.). Therefore, 4-day-old L. trifolii and 5-day-old L. bryoniae larvae were used in the experiments.

\section{Host pupal size}

To estimate the size of the pupa of the two Liriomyza species, the head width of 15 pupae within their puparia was measured to the nearest $6.7 \mu \mathrm{m}$ under a binocular stereomicroscope.

\section{Host suitability}

The base of the stem of a $P$. vulgaris plant with two true leaves infested with approximately 20-30 4-day-old larvae of $L$. trifolii or 5-day-old larvae of $L$. bryoniae was immersed in water in a $10-\mathrm{ml}$ glass vial attached to the inside bottom of a cylindrical glass tube $(6.4 \mathrm{~cm}$ diameter, $22 \mathrm{~cm}$ high). The top of the tube was covered with organdy and the bottom with Kimwipe ${ }^{\circledR}$. Undiluted honey was streaked on the inside of the tube as a food source for the wasps. Immediately thereafter, one naive female G. micromorpha (0-24 h old) was released into the tube and allowed to parasitize the Liriomyza larvae for $24 \mathrm{~h}$ before removal from the tube. Fifteen wasps were used for each Liriomyza species. After removal of the wasp, the two leaves were detached from each plant by cutting the petioles and then placed in a $250-\mathrm{ml}$ plastic cup. The immatures of Liriomyza were reared and the emergence of $G$. micromorpha wasps recorded. The hind tibial lengths of 20 randomly selected wasps emerging from each host species were measured to the nearest $6.7 \mu \mathrm{m}$ under a binocular microscope.

\section{Host acceptance}

Phaseolus vulgaris plants with two true leaves were infested with mature larvae of L. trifolii or L. bryoniae as in the previous experiment. Just before the experiment, one of the two true leaves was cut from each plant. The stems of one plant with mature larvae of $L$. trifolii and one with mature larvae of $L$. bryoniae were immersed in water in a $10-\mathrm{ml}$ glass vial attached to the bottom of a glass tube (as above). Immediately after transfer of the plants, one 0-24 h-old naive female G. micromorpha was introduced into the tube and allowed to oviposit into $L$. trifolii and L. bryoniae larvae for $24 \mathrm{~h}$ before removal. After removal of the wasp, all host larvae were transferred from the leaves into Ringer's solution and dissected with minute pins under a binocular microscope to see whether they contained parasitoid eggs or not. Twenty replicates were performed. The ratio of the number of the two host species (L. trifolii / L. bryoniae) per replicate ranged from 0.54 to 2.12 .

\section{Host acceptance and larval survival}

The experimental design was the same as in the host acceptance experiment, except that the host larvae were reared after exposure to G. micromorpha and the emergence of adult parasitoids was recorded. After the end of adult emergence, host puparia with no exit holes were dissected under a binocular microscope to record mortality of L. trifolii and L. bryoniae pupae, and larval, pupal, or adult mortality of G. micromorpha. Twenty replicates were performed. The ratio of the two host species (L. trifolii / L. bryoniae) per replicate ranged from 0.72 to 3.33 .

\section{Data analysis}

One-way ANOVA was used to detect differences in pupal head width between $L$. trifolii and L. bryoniae. Effects of host species on developmental time and body size of G. micromorpha were analyzed using the same statistical tests. Host acceptance and combined effects of host acceptance and larval survival of G. micromorpha were analyzed in paired T-test after weighting data for proportional availability of hosts. The significance level for all statistical tests was set at $\mathrm{P}=0.05$.

\section{RESULTS}

\section{Host pupal size}

The mean $( \pm \mathrm{SE})$ pupal head widths of $L$. trifolii and $L$. bryoniae were significantly different: $0.590( \pm 0.013) \mathrm{mm}$ and $0.655( \pm 0.014) \mathrm{mm}$, respectively (ANOVA, F = 11.802, d.f. $=1, \mathrm{P}<0.01)$.

\section{Host suitability}

All the wasps that emerged were females. No significant difference was found in the developmental time of G. micromorpha (measured from oviposition to adult emergence) between L. trifolii and L. bryoniae (Table 1, ANOVA, $F=3.206$, d.f. $=1, \mathrm{P}>0.05)$. The hind tibiae of wasps emerging from $L$. bryoniae puparia were significantly longer (difference $=0.024 \mathrm{~mm}$ ) than those emerging from L. trifolii puparia (Table 1, ANOVA, F = 7.659, d.f. $=1, \mathrm{P}<0.01)$. 
TABLE 1. Effect of host species on developmental time (mean $\pm \mathrm{SE}$ ) and hind tibial length (mean $\pm \mathrm{SE}$ ) of Gronotoma micromorpha.

\begin{tabular}{lcc}
\hline Host species & $\begin{array}{c}\text { Developmental time } \\
(\text { egg-adult) in days }\end{array}$ & Hind tibial length $(\mathrm{mm})$ \\
\hline L. trifolii & $19.3 \pm 0.1(\mathrm{n}=217) \mathrm{a}$ & $0.412 \pm 0.006(\mathrm{n}=20) \mathrm{a}$ \\
L. bryoniae & $19.1 \pm 0.1(\mathrm{n}=156) \mathrm{a}$ & $0.436 \pm 0.006(\mathrm{n}=20) \mathrm{b}$ \\
\hline
\end{tabular}

Means with the same letter were not significantly different in one-way ANOVA $(\mathrm{P}>0.05)$.

\section{Host acceptance}

Significantly more L. bryoniae than L. trifolii larvae were parasitized by G. micromorpha (Table 2, paired T-test, $t=-2.818$, d.f. $=19, \mathrm{P}=0.01)$.

\section{Host acceptance and larval survival}

There was no significant difference in rate of emergence of G. micromorpha between L. trifolii and L. bryoniae (Table 3, paired T-test, $t=-0.394$, d.f. $=19, \mathrm{P}>$ $0.05)$. No dead larvae, pupae, or adults of G. micromorpha were found in the dissected host puparia. These puparia contained only dead host pupae.

\section{DISCUSSION}

Gronotoma micromorpha completed its development successfully in both $L$. trifolii and L. bryoniae. No signifi- cant difference was found in the developmental time of this wasp in the two host species. However, larger $G$. micromorpha adults emerged from $L$. bryoniae than from L. trifolii puparia. Developmental time (or developmental rate) and body size are both important traits for evaluating fitness of parasitoids (Roitberg et al., 2001). In solitary koinobiont parasitoids, the size of the offspring is often influenced by the host species from which it emerged (Visser, 1994). Pupae of L. trifolii and L. bryoniae can be regarded as fixed host resources available for offspring development of G. micromorpha, because the parasitoid is in the 1st instar when the host pupates (Abe, Y., unpubl.). Pupae of L. bryoniae were significantly larger than those of L. trifolii. Large hosts presumably contain more resources and, therefore, should be of relatively higher quality than small hosts (Nicol \& Mackauer, 1999). Consequently, the difference in body size of $G$. micromorpha is probably due to the difference in the size of pupae of the two host species. Similarly, no significant difference was found in female developmental time of $D$. sibirica in L. trifolii and L. bryoniae, and larger parasitoid females emerged from $L$. bryoniae than from $L$. trifolii puparia (Abe et al., 2005). This difference in female size might be also explained by the higher quantity of food available in L. bryoniae.

TABLE 2. Acceptability of L. trifolii and L. bryoniae as hosts for G. micromorpha.

\begin{tabular}{|c|c|c|c|c|c|c|}
\hline \multirow[t]{2}{*}{ Replicate } & \multicolumn{2}{|c|}{$\begin{array}{l}\text { Number of larvae parasitized / } \\
\text { Number of larvae exposed }\end{array}$} & \multicolumn{2}{|c|}{ Proportional availability of hosts } & \multicolumn{2}{|c|}{$\begin{array}{l}\text { Number of larvae parasitized / } \\
\text { Proportional availability of host }\end{array}$} \\
\hline & L. trifolii & L. bryoniae & L. trifolii & L. bryoniae & L. trifolii & L. bryoniae \\
\hline 1 & $5 / 29$ & $12 / 23$ & 0.558 & 0.442 & 8.96 & 27.15 \\
\hline 2 & $18 / 19$ & $8 / 13$ & 0.594 & 0.406 & 30.30 & 19.70 \\
\hline 3 & $11 / 45$ & $11 / 26$ & 0.634 & 0.366 & 17.35 & 30.05 \\
\hline 4 & $4 / 21$ & $14 / 39$ & 0.350 & 0.650 & 11.43 & 21.54 \\
\hline 5 & $10 / 19$ & $3 / 9$ & 0.679 & 0.321 & 14.73 & 9.35 \\
\hline 6 & $14 / 27$ & $5 / 14$ & 0.659 & 0.341 & 21.24 & 14.66 \\
\hline 7 & $5 / 20$ & $12 / 33$ & 0.377 & 0.623 & 13.26 & 19.26 \\
\hline 8 & $9 / 23$ & $13 / 27$ & 0.460 & 0.540 & 19.57 & 24.07 \\
\hline 9 & $12 / 22$ & $16 / 27$ & 0.449 & 0.551 & 26.73 & 29.04 \\
\hline 10 & $19 / 25$ & $9 / 12$ & 0.676 & 0.324 & 28.11 & 27.78 \\
\hline 11 & $9 / 15$ & $11 / 14$ & 0.517 & 0.483 & 17.41 & 22.77 \\
\hline 12 & $3 / 21$ & $16 / 35$ & 0.375 & 0.625 & 8.00 & 25.60 \\
\hline 13 & $14 / 29$ & $9 / 21$ & 0.580 & 0.420 & 24.14 & 21.43 \\
\hline 14 & $4 / 25$ & $18 / 24$ & 0.510 & 0.490 & 7.84 & 36.73 \\
\hline 15 & $4 / 17$ & $17 / 24$ & 0.415 & 0.585 & 9.64 & 29.06 \\
\hline 16 & $9 / 23$ & $9 / 16$ & 0.590 & 0.410 & 15.25 & 21.95 \\
\hline 17 & $10 / 21$ & $8 / 13$ & 0.618 & 0.382 & 16.18 & 20.94 \\
\hline 18 & $4 / 26$ & $13 / 15$ & 0.634 & 0.366 & 6.31 & 35.52 \\
\hline 19 & $11 / 21$ & $5 / 11$ & 0.656 & 0.344 & 16.77 & 14.53 \\
\hline 20 & $9 / 26$ & $6 / 15$ & 0.634 & 0.366 & 14.20 & 16.39 \\
\hline
\end{tabular}

Mean ( \pm SE) of the number of larvae parasitized/proportional availability of hosts for L. trifolii and L. bryoniae were 16.37 ( \pm 1.56$)$ and $23.38( \pm 1.56)$, respectively. There was a significant difference in acceptability of these two hosts (paired T-test, $t=-2.818$, d.f. $=19, \mathrm{P}=0.01)$. 
TABLE 3. Combined effects of host acceptability and offspring survival on the number of G. micromorpha that emerged from $L$. trifolii and L. bryoniae.

\begin{tabular}{|c|c|c|c|c|c|c|}
\hline \multirow[t]{2}{*}{ Replicate } & \multicolumn{2}{|c|}{$\begin{array}{l}\text { Number of wasps emerging / } \\
\text { Number of larvae exposed }\end{array}$} & \multicolumn{2}{|c|}{ Proportional availability of hosts } & \multicolumn{2}{|c|}{$\begin{array}{l}\text { Number of wasps emerging / } \\
\text { Proportional availability of hosts }\end{array}$} \\
\hline & L. trifolii & L. bryoniae & L. trifolii & L. bryoniae & L. trifolii & L. bryoniae \\
\hline 1 & $14 / 24$ & $7 / 32$ & 0.429 & 0.571 & 32.63 & 12.26 \\
\hline 2 & $15 / 16$ & $9 / 13$ & 0.552 & 0.448 & 27.17 & 20.09 \\
\hline 3 & $6 / 16$ & $10 / 15$ & 0.516 & 0.484 & 11.63 & 20.66 \\
\hline 4 & $11 / 16$ & $7 / 17$ & 0.485 & 0.515 & 22.68 & 13.59 \\
\hline 5 & $16 / 18$ & $8 / 12$ & 0.600 & 0.400 & 26.67 & 20.00 \\
\hline 6 & $17 / 27$ & $5 / 12$ & 0.692 & 0.308 & 24.57 & 16.23 \\
\hline 7 & $4 / 13$ & $6 / 15$ & 0.464 & 0.536 & 8.62 & 11.19 \\
\hline 8 & $5 / 13$ & $8 / 16$ & 0.448 & 0.552 & 11.16 & 14.49 \\
\hline 9 & $5 / 18$ & $5 / 25$ & 0.419 & 0.581 & 11.93 & 8.61 \\
\hline 10 & $10 / 14$ & $8 / 11$ & 0.560 & 0.440 & 17.86 & 18.18 \\
\hline 11 & $13 / 33$ & $8 / 30$ & 0.524 & 0.476 & 24.81 & 16.81 \\
\hline 12 & $0 / 24$ & $13 / 23$ & 0.511 & 0.489 & 0 & 26.58 \\
\hline 13 & $7 / 25$ & $6 / 20$ & 0.556 & 0.444 & 12.59 & 13.51 \\
\hline 14 & $5 / 15$ & $6 / 8$ & 0.652 & 0.348 & 7.67 & 17.24 \\
\hline 15 & $6 / 34$ & $6 / 20$ & 0.630 & 0.370 & 9.52 & 16.22 \\
\hline 16 & $7 / 30$ & $4 / 9$ & 0.769 & 0.231 & 9.10 & 17.32 \\
\hline 17 & $4 / 23$ & $4 / 19$ & 0.548 & 0.452 & 7.30 & 8.85 \\
\hline 18 & $6 / 33$ & $7 / 14$ & 0.702 & 0.298 & 8.55 & 23.49 \\
\hline 19 & $13 / 23$ & $3 / 21$ & 0.523 & 0.477 & 24.86 & 6.29 \\
\hline 20 & $0 / 21$ & $9 / 20$ & 0.512 & 0.488 & 0 & 18.44 \\
\hline
\end{tabular}

Mean $( \pm \mathrm{SE})$ of the number of wasps emerging / proportional availability of hosts for L. trifolii and L. bryoniae were $14.97( \pm 2.11)$ and $15.87( \pm 1.19)$, respectively. There was no significant difference in the number of wasps emerging from these two host species (paired T-test, $t=-0.394$, d.f. $=19, \mathrm{P}>0.05$ ).

A female parasitoid can influence the fitness of her offspring through her choice of a host, since the quality of the host can directly affect offspring fitness (Luck \& Nunney, 1999). Thus, it is predicted that foraging female parasitoids that encounter hosts of different species should select the most suitable. Female G. micromorpha exhibited a significant preference for $L$. bryoniae larvae. However, no significant difference was found in the number of wasps emerging between $L$. trifolii and L. bryoniae. These results indicate that G. micromorpha immatures parasitizing $L$. bryoniae had a higher mortality rate than those parasitizing L. trifolii. Why do female $G$. micromorpha prefer L. bryoniae larvae, which are of a lower quality than $L$. trifolii larvae in terms of their offspring's survival? It is possible that $L$. bryoniae larvae are a better quality host than L. trifolii larvae in terms of the fecundity of wasp's offspring. In general, large parasitoids are more fecund than small ones (King, 1987; Visser, 1994). Provided the size and fecundity of female $G$. micromorpha are positively correlated, as in female $D$. sibirica (Croft \& Copland, 1993), female G. micromorpha emerging from $L$. bryoniae puparia would have a higher fecundity than those from L. trifolii puparia. Further study is needed to clarify the relationship between the size and fecundity in female G. micromorpha.
The geographical distributions of $L$. bryoniae and $G$. micromorpha do not overlap. However, the present study reveals that $L$. bryoniae is as good as $L$. trifolii as a host for G. micromorpha in terms of larval development and survival and is the preferred host for oviposition. These three factors are important for biological control because they influence a parasitoid's parasitism rate and its numerical response. In addition to the wide range of host stages (egg to mature larvae) suitable for oviposition (Abe, 2001), the reproductive capacity and no adverse effect of high temperature or short photoperiod on development (Abe \& Tahara, 2003), the present results indicate that $G$. micromorpha could be an effective biological control agent of $L$. trifolii and L. bryoniae in greenhouses.

ACKNOWLEDGEMENTS. I would like to thank H. Takada and Y. Yoshiyasu for their suggestions. Thanks are also due to E. Tada for providing the founder specimens of L. bryoniae.

\section{REFERENCES}

ABE Y. 2001: Egg-pupal and larval-pupal parasitism in the parasitoid Gronotoma micromorpha (Hymenoptera: Eucoilidae). Appl. Entomol. Zool. 36: 479-482.

Abe Y. \& Kawahara T. 2001: Coexistence of the vegetable leafminer, Liriomyza sativae (Diptera: Agromyzidae), with L. 
trifolii and L. bryoniae on commercially grown tomato plants. Appl. Entomol. Zool. 36: 277-281.

ABE Y. \& TAhara M. 2003: Daily progeny production and thermal influence on development and adult longevity of the leafminer parasitoid, Gronotoma micromorpha (Hym., Eucoilidae). J. Appl. Entomol. 127: 477-480.

AbE Y. \& Konishi K. 2004: Taxonomic notes on Gronotoma (Hymenoptera: Eucoilidae) parasitic on the serpentine leafminer, Liriomyza trifolii (Diptera: Agromyzidae). Esakia 44: $103-110$.

Abe Y., Takeuchi T., Tokumaru S. \& Kamata J. 2005: Comparison of the suitability of three pest leafminers (Diptera: Agromyzidae) as hosts for the parasitoid Dacnusa sibirica (Hymenoptera: Braconidae). Eur. J. Entomol. 102: 805-808.

ARAKAKI N., OISHI T. \& NoDA H. 2001: Parthenogenesis induced by Wolbachia in Gronotoma micromorpha (Hymenoptera: Eucoilidae). Entomol. Sci. 4: 9-15.

BEARDSLEY JR. J.W. 1988: Eucoilid parasites of agromyzid leafminers in Hawaii (Hymenoptera: Cynipoidea). Proc. Hawaii. Entomol. Soc. 28: 33-47.

Croft P. \& Copland M.J.W. 1993: Size and fecundity in Dacnusa sibirica Telenga. IOBC WPRS Bull. 16: 53-56.

Heinz K.M. \& Parrella M.P. 1990: The influence of host size on sex ratios in the parasitoid Diglyphus begini (Hymenoptera: Eulophidae). Ecol. Entomol. 15: 391-399.

JoHnson M.W. 1993: Biological control of Liriomyza leafminers in the Pacific Basin. Micronesica (Suppl.) 4: 81-92.

KING B.H. 1987: Offspring sex ratios in parasitoid wasps. Quart. Rev. Biol. 62: 367-396.

KonISHI K. 1998: An illustrated key to the hymenopterous parasitoids of Liriomyza trifolii in Japan. Misc. Pub. Nat. Inst. Agro-Environ. Sci. 22: 27-76 (in Japanese).

Ledieu M.S. \& Helyer N.L. 1985: Observations on the economic importance of tomato leaf miner (Liriomyza bryoniae) (Agromyzidae). Agric. Ecosyst. Environ. 13: 103-109.

LuCK R.F. \& NunNEY L. 1999: A Darwinian view of host selection and its practical implications. In Hawkins A. \& Cornell H.V. (eds): Theoretical Approaches to Biological Control. Cambridge University Press, Cambridge, UK, pp. 283-303.

Malais M. \& Ravensberg W.J. 1991: The Biology of Glass House Pests and Their Natural Enemies, Knowing and Recognizing. (Yano E. et al. transl., 1995). Nosan-gyoson-bunkakyokai, Tokyo, 116 pp. (in Japanese).

MinKENBERG O.P.J.M. 1989: Temperature effects on the life history of the eulophid wasp Diglyphus isaea, an ectoparasitoid of leafminers (Liriomyza spp.), on tomatoes. Ann. Appl. Biol. 115: 381-397.

MinkENBERg O.P.J.M. 1990: Reproduction of Dacnusa sibirica (Hymenoptera: Braconidae), an endoparasitoid of leafminer Liriomyza bryoniae (Diptera: Agromyzidae) on tomatoes, at constant temperatures. Environ. Entomol. 19: 625-629.

Minkenberg O.P.J.M. \& van Lenteren J.C. 1986: The leafminers Liriomyza bryoniae and L. trifolii (Diptera: Agro- myzidae), their parasites and host plants: a review. Agric. Univ. Wageningen Pap. 86(2): 1-50.

Nicol C.M.Y. \& Mackauer M. 1999: The scaling of body size and mass in a host-parasitoid association: influence of host species and stage. Entomol. Exp. Appl. 90: 83-92.

Ozawa A., Saito T. \& Ota M. 2001: Biological control of the American serpentine leafminer, Liriomyza trifolii (Burgess), on tomato in greenhouses by parasitoids. II. Evaluation of biological control by Diglyphus isaea (Walker) and Dacnusa sibirica Telenga in commercial greenhouses. Jpn. J. Appl. Entomol. Zool. 45: 61-74 (in Japanese).

Rathman R.J., Johnson M.W. \& Tabashnik B.E. 1991: Production of Ganaspidium utilis (Hymenoptera: Eucoilidae) for biological control of Liriomyza spp. (Diptera: Agromyzidae). Biol. Control 1: 256-260.

Roitberg B.D., Boivin G. \& Vet L.E.M. 2001: Fitness, parasitoids, and biological control: an opinion. Can. Entomol. 133: 429-438.

SAITo T. 1997: [Liriomyza trifolii]. Nosan-gyoson-bunka-kyokai, Tokyo, 103 pp. (in Japanese).

Sasakawa M. 1961: A study of the Japanese Agromyzidae (Diptera), Part 2. Pacif. Ins. 3: 307-472.

Spencer K.A. 1973: Agromyzidae (Diptera) of Economic Importance. Dr. W. Junk, The Hague, 405 pp.

StOUthamer R. 1993: The use of sexual versus asexual wasps in biological control. Entomophaga 38: 3-6.

TAKADA H. \& KamiJo K. 1979: Parasite complex of the garden pea leaf-miner, Phytomyza horticola Gourea, in Japan. Kontyu 47: 18-37.

ToKumaru S. \& ABE Y. 2003: Effects of temperature and photoperiod on development and reproductive potential of Liriomyza sativae, L. trifolii, and L. bryoniae (Diptera: Agromyzidae). Jpn. J. Appl. Entomol. 47: 143-152 (in Japanese).

van Lenteren J.C., Babendreier D., Bigler F., Burgio G., HokKANen H.M.T., Kuske S., Loomans A.J.M., MenzlerHokkanen I., van Rijn P.C.J., Thomas M.B., Tommasini M.G. \& ZENG Q.-Q. 2003: Environmental risk assessment of exotic natural enemies used in inundative biological control. BioControl 48: 3-38.

VISSER M.E. 1994: The importance of being large: the relationship between size and fitness in females of the parasitoid Aphaereta minuta (Hymenoptera: Braconidae). J. Anim. Ecol. 63: 963-978.

Williamson M. 1996: Biological Invasions. Chapman \& Hall, London, $244 \mathrm{pp}$.

YANO E. 1993: Prospects for biological control in protected crops in Japan. OILB/SROP Bull. 16: 189-192.

Yosнiмото C.M. 1963: Synopsis of Polynesian Cynipoidea (Hymenoptera: Eucoilinae). Pacif. Ins. 5: 433-443.

Received October 6, 2004; revised and accepted June 8, 2005 